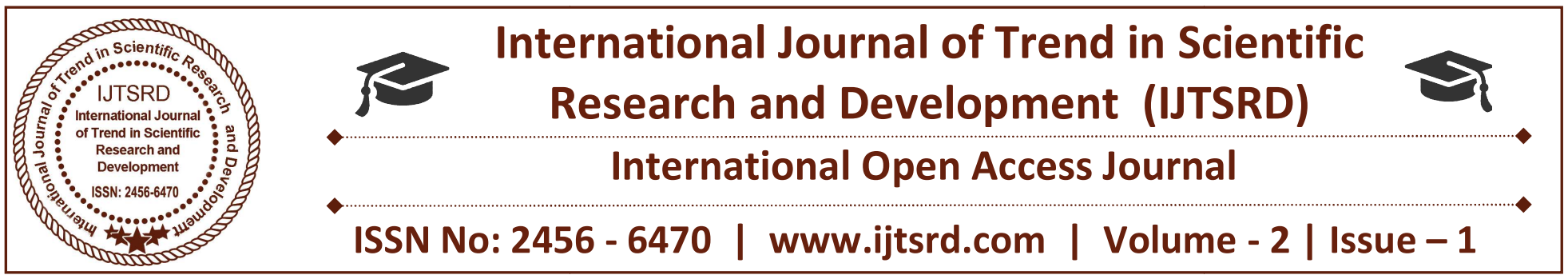

\title{
Design and Implementation of a Web-Based Prisons Management and Police Investigation System
}

\author{
Amadi Christopher C, Aguodoh P.C and Amaugo Noble \\ Department of Computer Engineering, Michael Okpara \\ University of Agriculture, Umudike Abia State, Nigeria
}

\section{ABSTRACT}

Information Technology (IT) has cut across all the areas of our society. In the light of this, I studied the Management Information System for Nigerian Prisons Service, Afara, Umuahia, Abia State with the aim of developing a software that can maintain an up-to-date record of inmates as well as rendering quick and efficient services to the prisoners and also aid the Nigerian Police Force (NPF) with a database of records for their investigations as concerns exconvicts. Bearing in mind that the management of most prisons in Nigeria is currently done manually. This manual process of managing the prison's records and procedures makes every available document prone to damage or theft. This project took time to go into relevant details within the scope and time frame to try and proffer quick and very affordable solution to this issue. This project was done using basic Hyper Text Markup Language (HTML) for visible web contents, javascript, Asp.Net for server scripting and MySQL database was used to store and manage the prisoner's records. The project was implemented successfully and the result obtained provides a single management system which integrates all the relevant information about a prisoner, staff and other implementable modules in a single project. It can easily be accessed by the NPF to get relevant details in cases that concerns ex-convicts or even prison officials.

Keywords: Hyper Text Markup Language, MySQL database, Javascript, Asp.net

\section{INTRODUCTION}

Prison management in Nigeria has not received adequate attention by the Government and to the society at large. It has been observed that the state of prison services in Nigeria continues to degrade at a very fast rate. Currently, the Prison in Afara, Umuahia has 910 male and 45 female inmates while the prison facility had the capacity to contain only 500 persons.

Currently, a rudimentary process of storing prisoners' data manually and registers is in place, necessitating a lot of records keeping for the inmates both in prison departments. These records house a very large number of inmates and their case details, such as: details of where they come from, records about the block and room they are allocated, health records and records of the people who come to visit them. Making the records environment explode with thousands of paper works in form of a manual file system, all of which must be managed. As a result, when a prisoner's report is needed, it takes longer time to produce to enable management make decisions. Oftentimes, reports disappear and tracing them becomes a problem since the system is not automated. Considering the administrative problems posed by most existing manually oriented system of information management and the security -oriented nature of the Nigerian prison services, manual procedures for the job execution brings about delay and reduces one's output. Also the sensitive information to be generated from the available data cannot be optimally utilized due to the sluggish and ineffective nature of the manual system.

As the technology evolution is consistently growing, an automated system would help management appreciate the benefits of efficient management of the Information System. Database technology would help managers and enable the management in every aspect 
of their operations in a coordinated and integrated way through access to structured data. There is a need for centralization of prisoners' data to facilitate information exchange and data sharing as well as the need for timely information to support management in making decisions. This calls for developing a prison records management information system as an answer to the above problems of managing prison records at Nigerian prison service Afara, Umuahia. This Management Information System will help the prison to cope with the increasing number of inmates, reduce administrative overheads, reduce risks involved in inmate's custody, eliminate obsolete processes, reap cost-cutting benefits and help the NPF classified information for investigations.

The Prison Management System seeks to integrate prisoners data into a single integrated system which will in turn result to all the information being present in a digital format; easy to understand, elegant, consistent and complete is required and implementation with a well-defined interface, data hiding, loose coupling, using passwords and usernames as security measure for data access from the system. Communication would be efficient and effective with the developed system. There would be tracking and monitoring of the Prisoners' details whenever required from the database. The Data entrant would capture data and be able to store it in the database for future retrieval anytime, anywhere by the Management. Also, the management would be able to control the system using security measures, through the privilege given by the administrator to read, write and edit as at when fit.

\section{LITERATURE REVIEW}

The prison is one place that needs the attention of every relevant authority, not just because of the nature or condition of the people in there but because the inmates are human beings who require love and prompt attention. As regards attention to the prison, the least we could do is to make sure that every process and happenings in the prison is well documented and taken care of to avoid loss of information. The growing trend and awareness to the populace that there are inmates who have not been tried in court or that there are prisoners who have long overstayed their jail time is a good one. But it gives birth to a huge question: how do they know who has overstayed if the records are lost? How do they get to know who and who has been properly charged to court following due process? From reliable sources, it is understood that a boy of fifteen (15) years was recently discharged from prison after spending two (2) years in prison. Who sends a thirteen year old boy to jail? These and some other issues prompted me to carry out a project about the automation of prison procedures and records to at least combat the possibility of loss of data or record or the misuse of information by any prisons personnel. Below are some of the relevant works done with the aim of automating the processes involved in the management of prisons all around the world and their drawbacks.

Nadatul 'IffahBintiAbuHasan (2008) from the faculty of Information and Communication Technology, UniversitiTeknikalMalaysia Melaka carried out a project on Prison Management System which he aimed at the Management of Prison processes. He aimed it to be a good collection of registers and reports for the effective management of prisons. His system was useful for users to manage and store the data of the prisoners. With the implementation of his project, the Prisons Department Malaysia had the ability to change the existing system to this system so that the database can do works more easy to ensure the data are completely secured and have a backup if something bad happens to the system and database.

The system also made sure that all the processes in the modules did the interfaces expected for the trigger module. The interfaces are links to the Oracle9i Database and the new data that inserted in the interface was stored in the database.

In addition, the Management System also created a safe way in the matter of managing the prisoner's information. This is due to the need of username and password in order to use the system. So, the System can be accessed only by authorized users. Thus, the system is protected from intrusion of unauthorized users. The limitation of this work however, is that the implementation was done on just a database of records stored locally in the different work stations in the prison. This breakthrough cannot be accessed from any other work station than the prisons where it was implemented. This is a major drawback to this breakthrough.

Harpreet et al (2002) postulated that the use of web or computer system could enhance organizations to improve on their communication and therefore effectiveness in service delivery. Likewise, Organizations and Institutions today are being forced 
by the Internet to move towards teleworking. Therefore, there is need for web-based computer system that could provide easy access of information online and also provide accessibility to information at any point in time. This necessitates management to access the database, which can be done by registering them into the system and then giving the privilege to them once logged-in while unauthorized users are denied access.

Rahul Singh, Snr. (2000) Implemented a Prison Management System at Arthur Road Prison and at other Prisons of Maharashtra for the Prison Department. The Prison Department, Government of Maharashtra has implemented Prison Management System (PMS) at Mumbai Central Prison and Mumbai District Prison, in the year 2010 on pilot basis, with a vision to scale up PMS to all prisons across Maharashtra. However, due to certain challenges, the department is in the process of evaluation of different options/solutions available to computerize different prisons across Maharashtra. For this project, access to the internet was an issue due to security reasons. Another issue was that at the expiration of their contract, terms were not renewed, hence the system broke down. Automation of existing process was done without considering process reengineering prior to automation of the process/sub-process. Initially, it was envisaged that if the PMS is successful, then it would be scaled up and may be implemented at various prisons across Maharashtra. But due to various reasons the implementation at Mumbai Central Prison is not considered a fully successful system. The government was not very supportive.

Adeyinka Adesuyi Falaye et al. (2013) developed a crime investigation system for the Nigeria Police Force using a biometrics approach. Reliable criminal suspects' recognition is an important problem in crime investigation process. The project was implemented using Visual Basic programming language. This project brought biometrics into the world of crime investigations management system but also has a major drawback, worldwide accessibility. If in the case of a fire outbreak or damage to the system on which the software carrying the database was installed, there would be a loss of information just like when everything is done manually. The field of engineering seeks not just for solution to every problem encountered but for long lasting solution for every encountered problem. This project does not satisfy this quest!
Audu Paul Ilemona (2013) designed an online prisons management system for the Nigeria Prisons Service Enugu as a case study. This project was done using basic html for visible web contents, Php for server scripting and MySQL database was used to store and manage the prisoner's records. A tool used to achieve this Project includes Dreamweaver CS5 html editor, CSS3 for styling, JavaScript, Php wamp5 server and MySQL. The project was implemented successfully and the result obtained provides a single management system which integrates all the information about a prisoner in a single profile and can easily be accessed which improved the overall efficiency of prison management. This project introduced Prisons Management System to the Online Community where the Prison's website serves two purposes of being a portal for visitors to come and find out the current happenings in the prisons and also a portal for the administrators of the prison to manage the prison. However, the drawback was that the tools used for the development of this project are not a cross-platform tool. Php is a server-side scripting language but does not encourage separation of concerns for the business models of the web application. Dreamweaver CS5 is another tool which served as an IDE for designing the web application. This increased the number of tools used and therefore, increased cost and productivity time. In the case of modifying the system once implemented, the only person that would do that would be the developer of the project because it is not cross-plat formed and easy to manipulate.

Iheji Godswill Nnamdi (2001). Designed a Proposed Prison Management System for Nigerian Prisons Service. This work was to serve as a prototype for the technological advancement and demonstration of the various use of ICT resources in the Police and Prisons Service. He implemented it with ASP.Net MVC 2 in 2001 as it was the most common MVC technology at that time. However, it was not adopted at that time because the advanced use of web-based systems was not seen as the next big thing in the computerization of processes in the law agencies.

Putting into consideration the successes and the failure factors of the aforementioned projects, I therefore, decided to carry out this project with the sole aim of improving on the errors accumulated by the people who have tried carrying out this project over time by innovating new procedures to make prisons management better. 
International Journal of Trend in Scientific Research and Development (IJTSRD) ISSN: 2456-6470

\section{MATERIALS AND METHODS}

\section{Materials}

\section{System Requirements}

\section{- Hardware Requirement}

1. Wired and Wireless connectivity capability for network hosts.

2. Processor $3.4 \mathrm{GHZ}$

3. Minimum Ram size $4 \mathrm{~GB}$

4. Minimum Hard drive 500GB

5. Computer Systems (Server, Laptop etc.)

\section{- Software Requirement}

1. Microsoft SQL Server 2012.

2. Web Browser (Google Chrome, Internet Explorer, Mozilla Firefox)

3. Internet Information Service (IIS 8.0) minimum.

4. Windows Server (Server OS).

5. Windows 8 and above (Laptop and Desktop).

\section{System Cost Analysis}

The basic requirements for the implementation of this system are shown below:

\section{Table 1: Hardware Requirement}

\begin{tabular}{|c|c|c|c|}
\hline $\begin{array}{l}\mathbf{S} / \\
\mathbf{N}\end{array}$ & $\begin{array}{l}\text { QUA } \\
\text { NTIT } \\
\text { Y }\end{array}$ & DETAILS & AMOUNT(N) \\
\hline 1. & & $\begin{array}{l}\text { Complete set of } \\
\text { computer system. } \\
\text { (Configuration } \\
\text { requirement: } \\
\text { 500GB }- \\
\text { Terabyte } \\
\begin{array}{l}\text { Disk, } \\
\text { RAM, }\end{array} \text { 12-4GB } \\
\text { Processor) }\end{array}$ & 90,000 \\
\hline 2. & 1 & $\begin{array}{l}\text { Uninterruptible } \\
\text { Power Supply } \\
\text { (UPS) }\end{array}$ & 8,000 \\
\hline 3. & 3 & Laser Jet Printers & 35,000 \\
\hline 4. & 1 & $\begin{array}{l}\text { Photocopier } \\
\text { TOTAL }\end{array}$ & $\begin{array}{l}50,000 \\
183,000\end{array}$ \\
\hline
\end{tabular}

Table 2: Software Requirement

\begin{tabular}{|l|l|l|l|}
\hline S/N & QUANTITY & DETAILS & AMOUNT \\
\hline 1. & 1 & $\begin{array}{l}\text { Microsoft Visual } \\
\text { Studio Software }\end{array}$ & 10,000 \\
\hline 2. & 1 & $\begin{array}{l}\text { Microsoft Office } \\
\text { Suite }\end{array}$ & 2,000 \\
\hline 3. & 1 & $\begin{array}{l}\text { Microsoft SQL } \\
\text { Server }\end{array}$ & 2,000 \\
\hline & & \begin{tabular}{l} 
Total \\
\hline
\end{tabular} & 14,000 \\
\hline
\end{tabular}

\section{Methods}

According to the oxford advanced learners dictionary, research can be defined as the careful study of a subject especially in order to discover new facts and information about it (i.e. subject matter). Methodology on the other hand, can be defined as a set of methods or principles used in performing a particular activity. Research methodology deals with the necessary methods undertaken to investigate the system thereby knowing its problem areas and gathering information necessary to implement the new and improved system which is proposed to curb off the existing problems. The importance of research methodology is to carefully design a module which will ensure that data for the analysis of the existing system is properly collected from the right and reliable source and such data is being also analyzed to ensure full understanding of the existing problem before any new system is designed. The essence of this is to avoid software crisis, of which research has shown that it is as a result of lack of thorough understanding of the existing systems (manual based system) before the design and implementation of any other improved web based system.

This research methodology is a structured approach which has detailed description of what the researcher planned and procedures adopted in gathering new facts relevant to the project. Through this structured approach, we can arrive at a dependable solution to problems through the planned and systematic collection, analysis and interpretation of data.

\section{Sources of Data}

This refers to the origin of the data obtained and used in the analysis of the system in this research work. The sources of data used can be broadly classified into two viz: 


\section{Primary Source}

2. Secondary Source

These two sources were used in this project in obtaining a reliable data used in the system analysis.

Primary Source: The primary source of data are the sampling or study units from which information is to be collected on first hand through interviews, measurement, observation, examination of the existing document, questionnaire collection. In this research work, much of the information that will be presented will be first-hand information.

a. Interviews: This is a process of getting information by means of conversion between the researcher and the interviewer(s). The special adviser to the comptroller of the prison was interviewed orally by the researcher (me) and information regarding to the process used in carrying out their daily routine and they talked about the efficiency level of the current system they are using. This interview was thoroughly done by the researcher so that a proper understanding of the existing system by the researcher can be established.

b. Observation: This is a primary source of data collection where the researcher either takes part in or watches a person perform activities in order to learn more about the system. For the fact that the complexity of certain aspects of the existing system prevents a clear explanation by the users, the researcher had to visit the Nigerian Prison Afara, Umuahia so as to be able to analyze and design the proposed system. This primary source of data helped the researcher to obtain reliable information about the existing system which helps in proper system analysis and design.

\section{c. Examination of the Existing Documents: Due to} the fact that the existing system needs to be properly understood for easy design and implementation of the web based system, most documents used in the prison were obtained from the relevant sections of the prison, examined and analyzed, most of these documents will help in the design of the user interface of the webbased system. Such documents examined include; inmates' personal data form, emergency treatment card, normal treatment card, doctor appointment booking form.

Secondary Source: The secondary source method of data collection is a method where the data are obtained indirectly unlike the primary source. Here, the researcher does not collect the data by themselves but rather makes use of existing literature, research reports, projects. Secondary information is therefore information that already exists or that have been collected, processed or reported by someone else. Data collection from this type of source has to be defect or lacking originality because of the high probability of the information being distorted. Due to this inherent demerit, only limited information was collected through this source.

\section{Choice of Analytical Method}

Having considered the models of analysis stated in chapter 2, the V-Model suits the project more. Bearing in mind that the V-Model provides means of testing of software at each stage in reverse manner in the case of a mistake, the choice of V-Model for this project is justified since a software project is bound to have some corrections or addition as the project proceeds so as to create a room for the client to modify his product specifications. The project of discourse is a Web-based Prisons Management System. This project includes different modules which represent sections of the prisons and the records that these respective sections are exposed to. In the course carrying out this project, some of the modules like the paroles and transfer modules were not included so it had to be included. Since this approach conforms to the V-Model of analysis, the choice of the V-Model is justified.

\section{System Reliability Requirements}

The reliability of the system comes from its ability to accept and process various user requests. The system should be reliable enough so that the data found in the database system is compatible at any condition. The system should also present a user interface which is interactive enough to aid easy navigation, usage and accessibility of required information. The process time of the codes must be efficient enough too so that time of accessing information won't take too long a time.

\section{Criticality of the Application}

The system is a web-based application and may not work effectively without the help of an intranet or internet connection. Whenever there is a loss in communication between the application and its database, then an erroneous output is expected. The system will not also deliver if the application or database server fails to work. The strength of the internet or intranet connection determines the 
processing speed of the application; hence, weak connection strength slows the system.

Physical design is the integration of all the designs (navigation, architectural, input and output) to generate a standard interface that captures all essential requirement specification to the later. Coding is done at this stage using ASP.Net programming paradigm. The coding phase ensures that all the requirement specification is turned into a functional application (Web Application). Microsoft Visual Studio provided the dot.Net (.Net) framework used in developing this Web Application. It is an Integrated Development Environment (IDE) that incorporates different .Net languages such as C-Sharp, Visual Basic, Java Script, ASP.NET and a test platform to test run at each stage of the development. The major software development tools used in this project are:
1. C\#.NET
2. Microsoft SQL 2012
3. ASP.NET.MVC 5
4. Web Browser
5. Microsoft Visual Studio 2012.

\section{Asp.Net Applications}

ASP.NET is a powerful technology used in creating dynamic web applications, often driven by a database. It is a Microsoft programming web toolkit. Many popular websites like www.myspace.com and www.asp.net were written using ASP.Net applications. It is a .NET technology. Developers write code in one of the several core .NET languages such as $\mathrm{CH}$, which is the programming language used in this work.

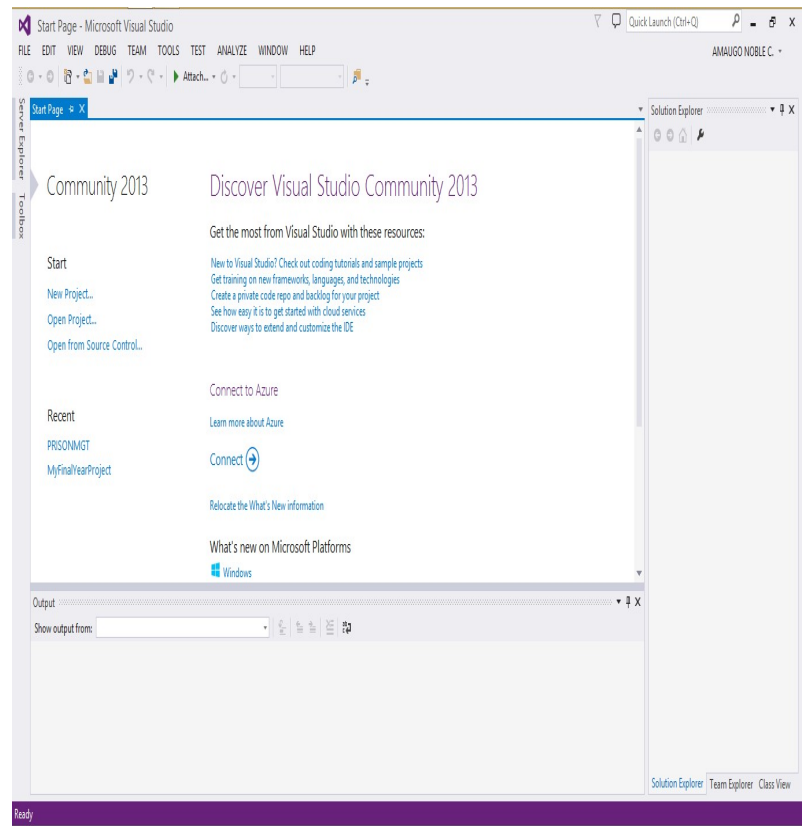

Visual Studio is a suite of applications created by Microsoft to give developers a compelling development environment for the Windows and .NET platforms. Visual Studio can be used to write console applications, Windows applications (ADO.NET), Windows services, Windows Mobile applications, ASP.NET applications, and ASP.NET web services, in your choice of $\mathrm{C}++, \mathrm{C} \#$, VB.NET, J\#, F\# and more.

\section{C-Sharp (C\#)}

Visual C\# is modern, high-level, general-purpose programming language for building Apps using Visual Studio and the .NET Framework. C\# is designed to be simple, powerful, type-safe, and object-oriented. $\mathrm{CH}$ is one of the programming languages designed for the Common Language Infrastructure (CLI).The Common Language Infrastructure is an open specification developed by Microsoft and standardized by ISO and ECMA that describes the executable code and runtime environment that form the core of the Microsoft .NET Framework and the free and open source implementations Mono and Portable.NET.

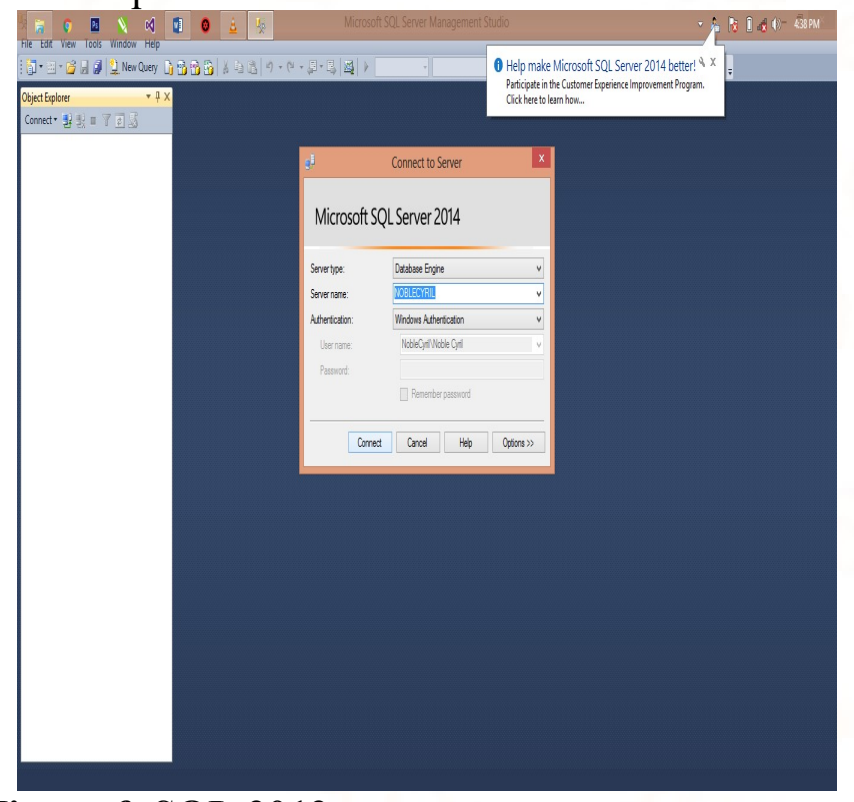

Microsoft SQL 2012

\section{RESULT}

After the design, the program is written and is implemented. The program source code needs to be tested with sample data to ascertain the programs validity and logical correctness locally on a workstation via the localhost technology. During this process, logical errors, syntax errors and other possible errors were seen and corrected. The aim of system implementation was to make sure that the right application was delivered to the end user and that the system built meets user requirements. Furthermore, 
this chapter also discusses the testing of the system to confirm that the user requirement is met. Moreover, during this testing period, the need for improvement of the programming codes and user interface were observed and necessary measures were taken to actualize and validate the processes.

The web based Prison Management system is aimed at providing a web based platform that will assist Prison Management with the provision of a high quality data security, orderliness and decorum, easy access to information on relevant medical records of inmates when needed and also make crime related data available. Below is the system flow chart for the Prison management and Police Investigation System.

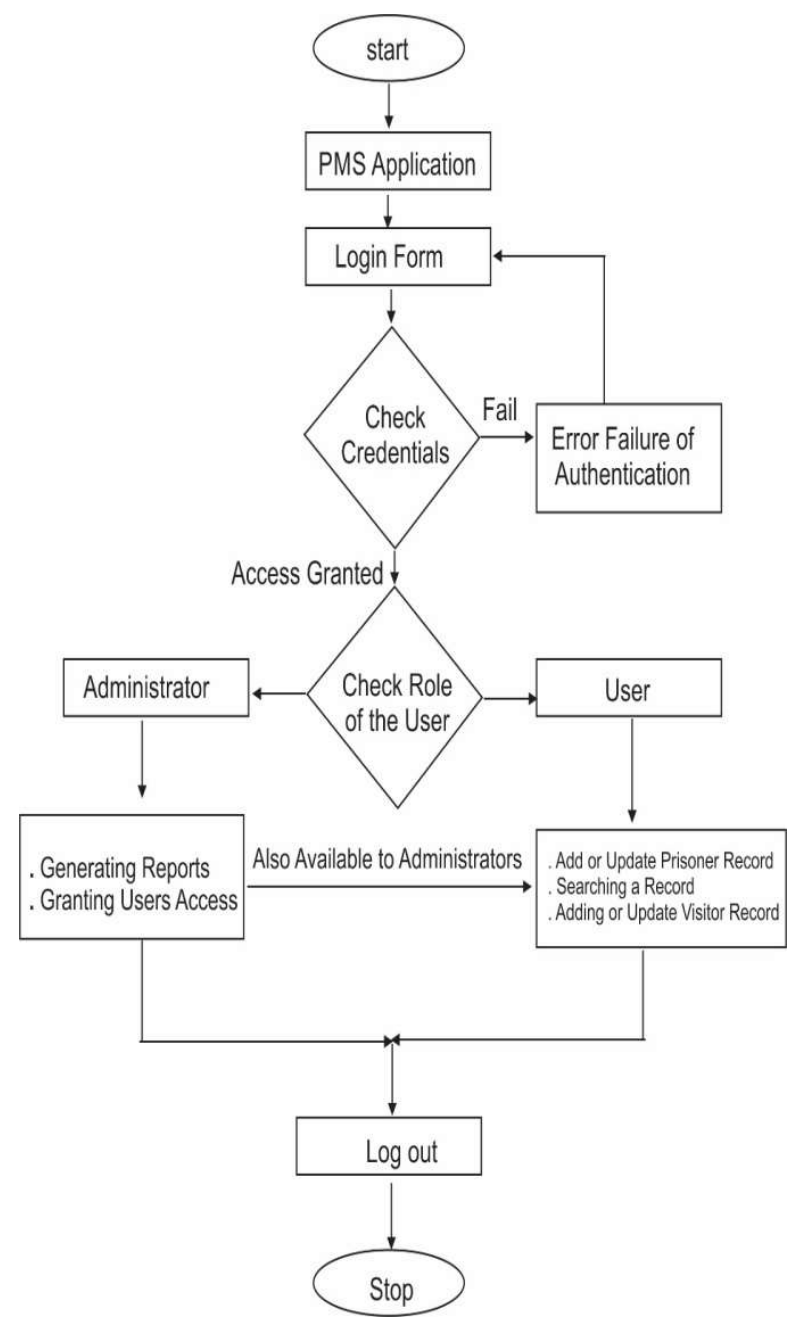

\section{System Flow Chart}

The architectural design for Web-based systems and applications focuses on the definition of the overall structure of the Web-based Application and the application of design patterns and constructive templates to populate the structure. In this design, a mixture of hierarchical and pure web structure was used to design the homepage to ease navigation.

\section{Navigation Design}

The Web-based Application designer creates a semantic navigation unit for each goal associated with each user role. Once the Web-based Application has been established and the components of the architecture have been identified, the designer must define navigation pathways to enable to access Webbased Application Services. The homepage of this application is one that informs the user the function of each link.

\section{Interface Design}

The user interface design incorporates the input, output and physical design. It gives the general layout procedure of the requirement procedure. Irrespective of the value of its content, and the complexity of its processing capabilities, a poorly design interface will make a potential user lose trust and confidence in the application.

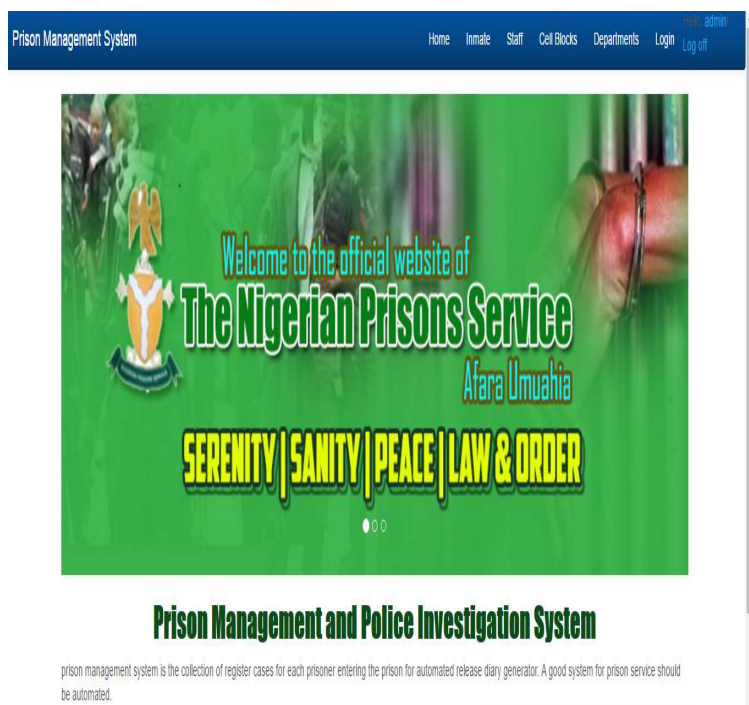

\section{Interface (Home Page) Design}

\section{Input Design}

This is the meeting point between the user and the application. The design input is necessary to control the amount of input, controlling errors, data validation, and keeping the system simple. Dropdown lists, Check Boxes, Radio Button List, represent input control for the input into web-based Application system. In this design, authorization is very essential to ensure monitoring of the system. The prison that uses the system will develop a login authorization page that will allow only authorized users to use the system and to ensure that abuse is not meted on the system. 
International Journal of Trend in Scientific Research and Development (IJTSRD) ISSN: 2456-6470

The login authorization was aimed at giving full access of the system to only users which the prison administrator(s) ensures that are fit to use the system.

\begin{tabular}{ll|}
\hline Surname \\
Surname \\
FirstName \\
Firstname \\
OtherNames \\
\hline
\end{tabular}

Date of Birth
DateofBirth

Email Address

Emailiaddress

\section{Address}

Address

PhoneNumber

PhoneNumber

Previous Employer

Input Design

\section{Output Design}

The output is the primary result of the sub-pages in the Application System homepage which draws its information from the database. Most of the output is as a result of user request for a particular page and this is often done by clicking a link or a selection in a dropdown list.

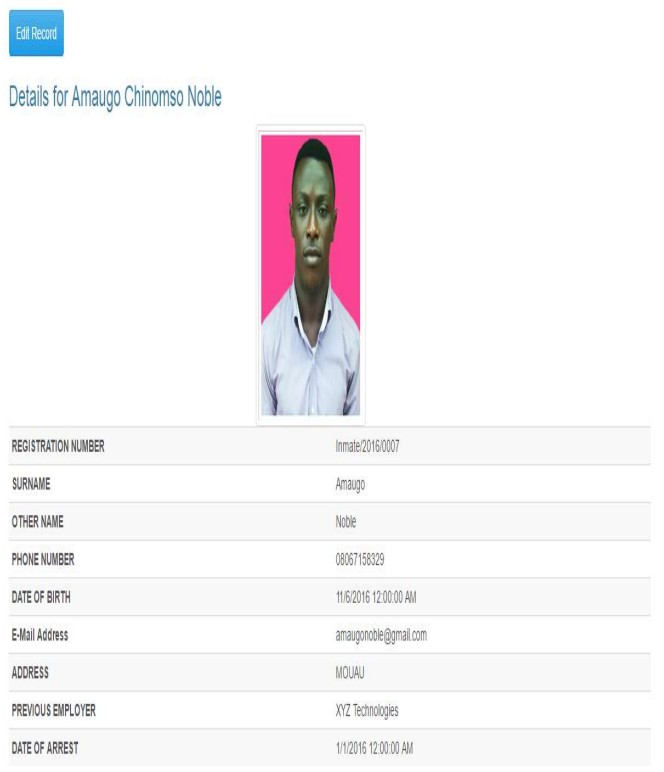

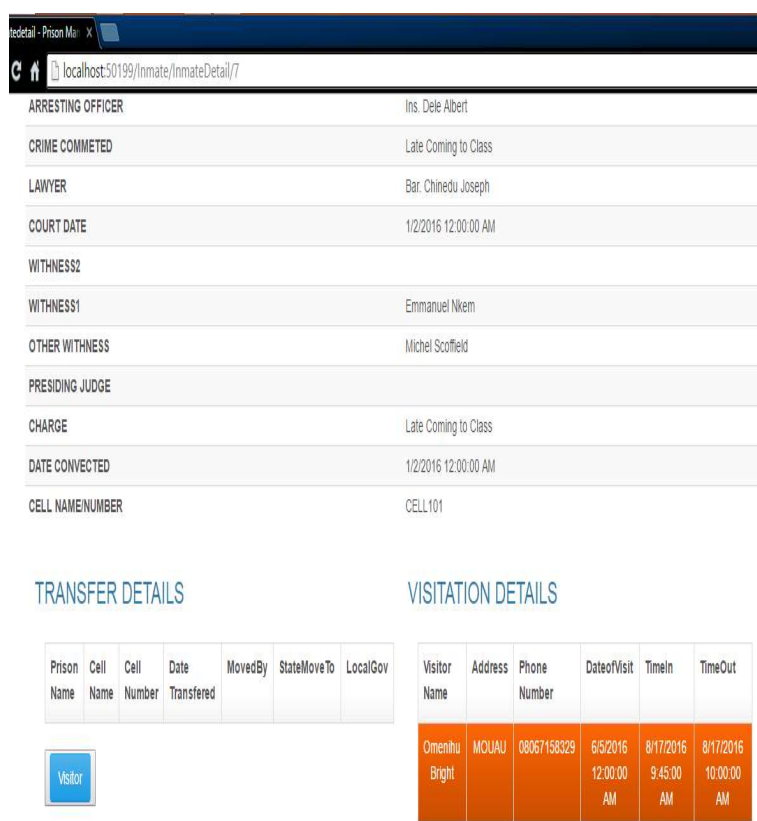

\section{Implementation Method}

There are different methods to deploy the new system. Examples:

- Setup

- X-copy

- Publish Web site

During the implementation of this system, publish web site was used. In publish, Asp.Net.Mvc4 application was configured in the Publish and Microsoft Visual Studio is where all the necessary settings were made.

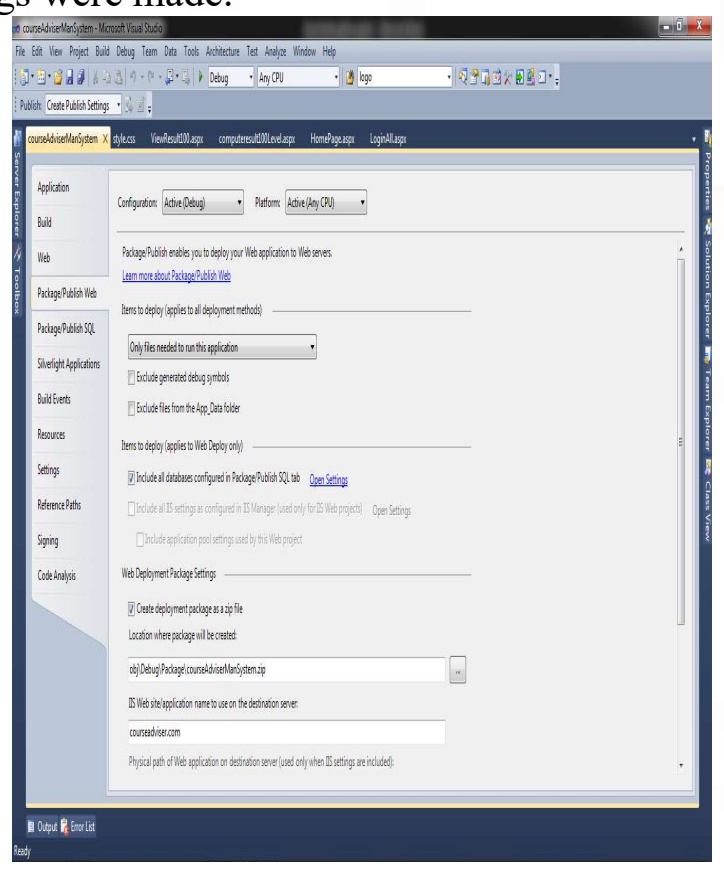

MS Visual Studio Publish/Settings Selection

The IIS(Internet Information Service) was setup and configured at the server end to help host the application on the server because the web server on its 
own cannot run C\# codes or process ASP.NET tags, when used in conjunction with any dynamic content such as ASP.NET.MVC. However, it's able to enlist the assistance of ASP.NET engine to perform all the heavy lifting.

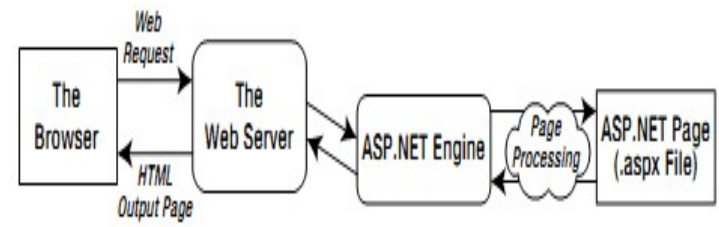

The interaction between ASP.Net page and a Web Browser

Furthermore, this process works for ASP.NeT pages. For example, when you request the page Default.aspx, the web server sends the request over to the ASP.NET engine (which starts automatically if needed). The ASP.NET engine loads the requested page, runs the code it contains, and then creates the final HTML document, which it passes back to IIS. IIS then sends the HTML document to the client. On the IIS the application is imported into the website root of the IIS. On the importation of the application, the IIS cross-checks the application to verify if it meets all the requirements needed to be hosted.

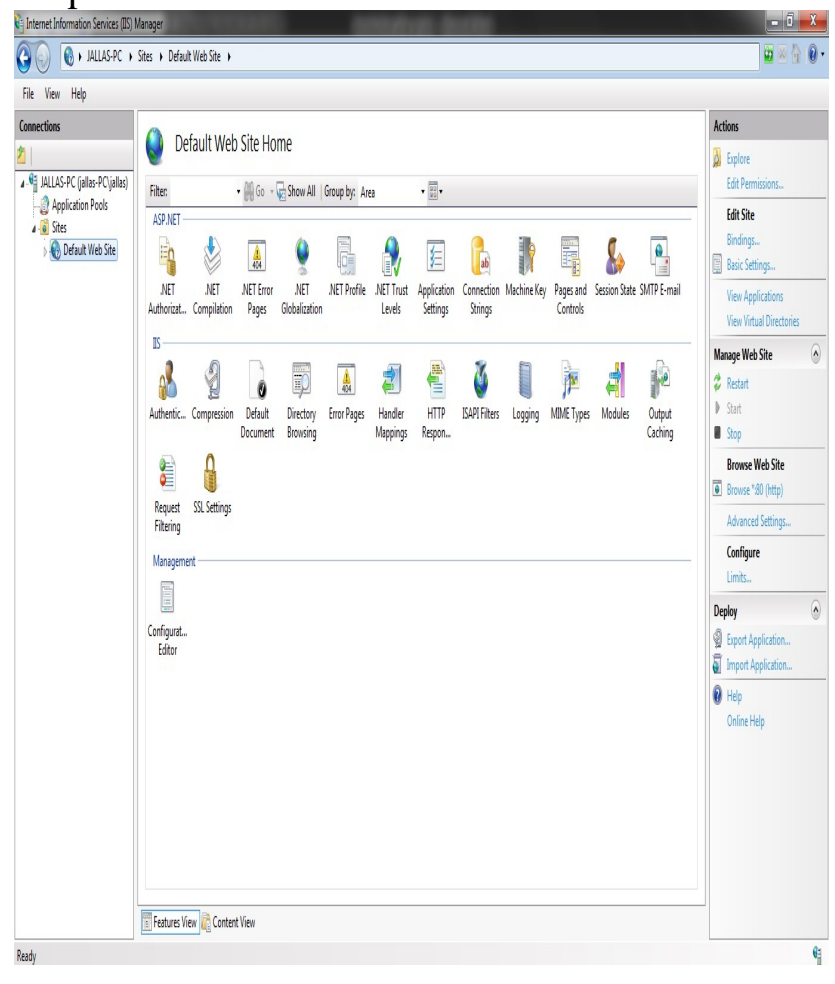

Internet Information Service (IIS) Page

The default Page is the first page to appear when the site is running. The directory browsing enables the directory in the site to be accessed while the application pool set the asp.net framework to be use by the site. After all this configuration the site is then launch to open in the web browser.

\subsubsection{Testing}

System testing is vital in Software Quality Assurance (SQA) and represents the ultimate review of specification, design and coding. Testing involves executing a program with the intent of finding an error. The purpose of testing is to identify and correct bugs in the developed system. Nothing is complete without testing. Testing is critical to the success of the system.

For this reason, every module of the program is executed to find an error. To perform specification test, the examination of the specifications stating what the program should do and how it should perform under various conditions.

Testing focuses first on the modules in the proposed system to locate errors, because it helps in detecting errors in the coding and logic that are contained within that module alone. Those resulting from the interaction between modules are initially avoided. In unit testing step each module has to be checked separately.

Testing on the system was not done as a whole, but rather module by module. The primary aim for testing individual module is to check the compatibility of individual modules. Testing and validation are the most important steps after the implementation of the developed system. The system testing is performed to ensure that there are no errors in the implemented system. The software must be executed several times in order to find out the errors in the different modules of the system.

Validation refers to the process of using the new software for the developed system in live environment i.e. using the developed system to archive prison data. The validation phase reveals the failures and the bugs in the developed system. It will come to know about the practical difficulties the system faces when operated in the true environment. By testing the code of the implemented software, the logic of the program was examined. A specification test is conducted to check whether the specifications stating the program are performing under various conditions

System Testing was done in 3 levels namely:

- Unit Level

- Module Level 
- Integration \& System

\section{Unit level testing}

Unit testing focuses on verification of the corresponding class or screen. This testing includes testing of control paths, interfaces, local data structures, logical decisions, boundary conditions, and error handling.

\section{Module level testing}

Module Testing is about testing each module of the software for easy debugging and to integrate all the modules together.

\section{Integration \& Testing}

System testing is used to verify, whether the developed system meets the requirements. Integration testing is used to verify the combining of the software modules. It addresses the issues associated with the dual problems of verification and program construction.

\section{Conclusion}

The rapid development of Information Technology has changed the way that systems can be developed and distributed. The essence of the web based Prisons Management System is to present a way to manage the sensitive information that runs across the bounds of the Nigerian prisons service, using the Nigerian Prison Service, Afara Umuahia as a case study and spring up an avenue to help the NPF with classified information. There is a growing trend in the Nigerian Prisons that some inmates overstay their sentence duration and hence, remain there for the foreseeable future. It is not in any way bad to repeat that this system under consideration would arrest so many of the anomaly faced as concerns the Prisons service. The proposed system would make sure that nobody would over stay their prison sentence and that there would not in any way, if managed properly, be a loss of information as every relevant information should have a cloud storage point via the internet.

The web based system considered above have a lot of prospect that will revive the declining level of service provision in Nigerian Prisons but this prospect comes with it, a great deal of challenges that will hinder a full implementation of the system under consideration. A careful analysis and adoption of all the proposed solution proffered in the paper will go a long way in handling the various challenges because there is a need to manage prisons records using web based solutions. A reduction in the number of lost files or irregularities is a major area of interest and would help monitor the progress of the system.

\section{REFERENCES}

1. Audu Paul Ilemona (2013). Design and Implementation of Online Prison Management System.

2. AdeyinkaAdesuyiFalaye et al. (2013). Crime investigation system for the Nigeria Police Force using a biometrics approach

3. Petersin, P. (2000). Computerization of management systems and records. London: Pearson Publication Limited.

4. James A.O'Brien, (1996), "Management Information Systems; Managing Information Technology in the Network Enterprise" $3^{\text {rd }}$ edition.

5. Davide, J. \& Gold P. (1994). Human Resource Management: Theory and Practice. London: Palgrave Macmillan.

6. Iheji Godswill Nnamdi (2001). A Design of a Proposed Prison Management System for Nigerian Prisons Service.

7. Jeffrey I., Whitten, et al(2001), "Systems Analysis and Design methods $5^{\text {th }}$ edition"

8. Robert R. Perkoski (1973) "Introduction to Web Development", Keewood Publishers, NY USA

9. Project Fiche (2007) - IPA Annual Action Programme for Bosnia and Herzegovina

10. Rahul Singh, Sr. Consultant, KPMG (2010). Prison Management System (Implementation at Arthur Road Prison and way forward for implementation at other Prisons of Maharashtra)

11. Evaluation Report on Project Titled Prison Management \& Information System (PMIS)

12. Gevana Lynn Salinas (2009), a preliminary Analysis: Prison Models and Prison Management Models and the Texas Prison System

13. MoshfeghHamedani for Udemy (2014). A stepby-Step Guide to ASP.Net

14. Hans-PetterHalvorsen (2014). ASP.Net and Web Programming

15. Rick Anderson and Scot Hanselman (2012). Introduction to ASP.Net MVC 4 with Visual Studio Beta

16. Nadatul 'IffahBinti Abu Hasan (2008), The Development of Prison Management System

17. Harpreet et al (2002), The use of Web or Computer System to Enhance Communication in Organisations 
18. Ray Brandy (2001), I.T and Macro electronics

19. Hughes (1994), The World Wide Web and its exciting Innovations

20. Prof. R.J Thacker (1996), Accounting Principles

21. Nwachukwu E.O (1998), Information System Development 